\title{
Topological and power characteristics of supercoiled DNA
}

\author{
A. V. Shirko, A. N. Kamluk \\ Belorussian state technological university, \\ Sverdlova str., 13 a, Minsk, Republic of Belarus, 220006 \\ a_shirko@tut.by
}

\begin{abstract}
The methods of elasticity theory were used to simulate topological properties of supercoiled DNA. A mechanism of realization of topological restrictions for supercoiled DNA was established. A possibility of transition from right hand to left hand DNA in strand molecules was theoretically proved. Influence of a corner strand on topological characteristics of a molecule was investigated. The parameters of force contact interaction in branches strand were defined.
\end{abstract}

Keywords: topologic, corner strand, right helical-left helical transition, force characteristics.

Introduction. In procariotic cells and eucariotic organelles the double helix forms a circular structure in such way, that two ends of the molecule are bound by covalent bindings. For this state of the molecular chain, the parameters characterizing DNA topology are fixed and can be only changed under influence of topoisomerases. Topological characteristics of the molecule can be experimentally changed by the inclusion in it the torsion or longitudinal stress. The torsion stress, for example, can be included by the following way: the ring DNA is split, then one end of the DNA is turned for some angle by outer twisting moment and the molecule is linked again. It is noticed, that by the achievement of some critical value of the twisting angle (see [1]) the supercoiled structure, which looks as a strand with the first supercoiling, is formed. We can also obtain the strand if one end of the linear

(C) Institute of Molecular Biology and Genetics NAS of Ukraine, 2009
DNA is fixed by the clamp and the other (free) end is turned for some angle. In this case the linear form of DNA loses its stability and the molecule comes into supercoiled state. The values of critical torsional moment and, therefore, torsional stress, which provide the instability of the linear form of DNA, depend on longitudinal stress induced by outer tensile force at the ends of the molecule [2].

As a result of theoretical investigation of the twisted molecules [3] it was established, that all equilibrium DNA configurations are represented as torus. However, when supercoiled ring DNA was studied under a microscope, it was found, that DNA was plectonomically self-plexiformed structure having some additional branched structures [4-6], which are called strands. Besides, according to [7], it was confirmed the conformation of DNA branches, which were twisted among themselves. These authors studied the structure of DNA solution using the methods of 
$\mathrm{X}$-ray scattering under small angle and cryoelectronic microscopy. The cause of this distinction between theory [3] and experiment [4-7] is the following: making theoretically the calculation of equilibrium forms, the authors [3] did not take into account the contact interaction between branches (i.e. they suggested, that DNA was able to "come through itself"). As it was shown in [8-10] the presence of self-contacts at the sites of DNA strand allowed to get equilibrium states with self-plexiform templates. These data were in accordance with the experiment. Therefore accounting of the contact interaction is very important for the research of plectonomically plexiform supercoiled DNA structures and we should not neglect it. Besides, the computational estimation of above mentioned contact interactions, which was done in the present paper, is of interest. DNA molecule in supercoiled plectonomical state is superhelical. It is induced by inner torsional and bending moments, which are appeared in DNA helix. The superhelix could be in this case positive or negative, depending on the direction of strand creation left-handed or right-handed.

As it was suggested in experimental work [11], the positively superhelical DNA can be transformed into Poling-like DNA (P-DNA) with sticking out nucleotide bases. The negative superhelix, likelihood, leads to the chain division in DNA molecule inducing double helix denaturation [12-13]. From the other hand, according to some observations [14], negative-superhelix can induce left-handed DNA formation. In our work we have investigated the influence of strand parameters on the force factors and topological characteristics of DNA. We have shown that formation of left-handed helix is possible in left-handed plectonomical strand,that proves the results obtained in [14]. To describe the topology of supercoiled molecules, the experimenters and theoreticians usually use the following equation [15]:

$$
\begin{aligned}
& \sigma=\left(L k-L k_{0}\right) / L k_{0} ; \\
& L k=W r+T w,
\end{aligned}
$$

where $\sigma$ - superhelix density; Lk- linking number, which is a topological invariant represented as polynomial number of intersections by one chain of the surface strained onto another chain; $\mathrm{Lk}_{0}$-linking number of the relaxed DNA; Wr- writhing number, i.e. the degree of spatial twisting of double helix axe; Twaxial twisting defined by the turn number, which one of the chain of double helix (sugar-phosphate backbone ) can do relatively the duplex axe. Wr exactly characterizes supercoiled DNA state (plectonomical strand), Lk determines its superhelix.

According to (2), it is obvious, that if we apply torsional moments to the linear molecule and the forces are sufficient to retain DNA in the stretched form, $\mathrm{Wr}=0$ and all superhelix takes only place thanks axial twisting, i.e. $\mathrm{Lk}=\mathrm{Tw}$. If stretching force is not sufficient to keep the molecule in the linear form, it loses its stability under influence of torsional moments and makes transition into supercoiled state forming plectonomical strand. In this case torsional stress acting in the strand branches leads to the formation positively $\left(\mathrm{Lk}>\mathrm{Lk}_{0}\right)$ or negatively $\left(\mathrm{Lk}<\mathrm{Lk}_{0}\right)$ superhelical DNA sites.

Topological properties of DNA (see (1) and (2)) are used by biologists as an initial point for the further investigations. The special feature our work is in the proposal to calculate and analyze the topological characteristics immediately on the base of our theoretical model.

So, main problems solved in the present work are the following: 1) theoretical ground of the transition from right-handed helix to left-handed DNA structure in the strand; 2) calculation of topological characteristics of DNA double helix at supercoiled state; 3) determination of inner force factors appearing in the brand branches.

Calculation scheme. We can consider the strand, which represents the site of supercoiled DNA. The axial line of the molecule in the strand is a regular helix with the angle $\beta_{\mathrm{s}}$, which is called strand angle (Fig. 1). All strand parameters are marked here with "s". To describe topology of DNA in the strand we have used our previous work [16], where the peculiarities of geometry of plectonomically plexiform DNA were defined. We have to notice, that in $[16,17]$ they solved the task making a suggestion, that any forces were not applied to the output (locking) loop (Fig. 1, right corner) and the strand angle $\beta_{\mathrm{s}}$ is constant along the length $1_{s}$. In this case to research geometry of the 


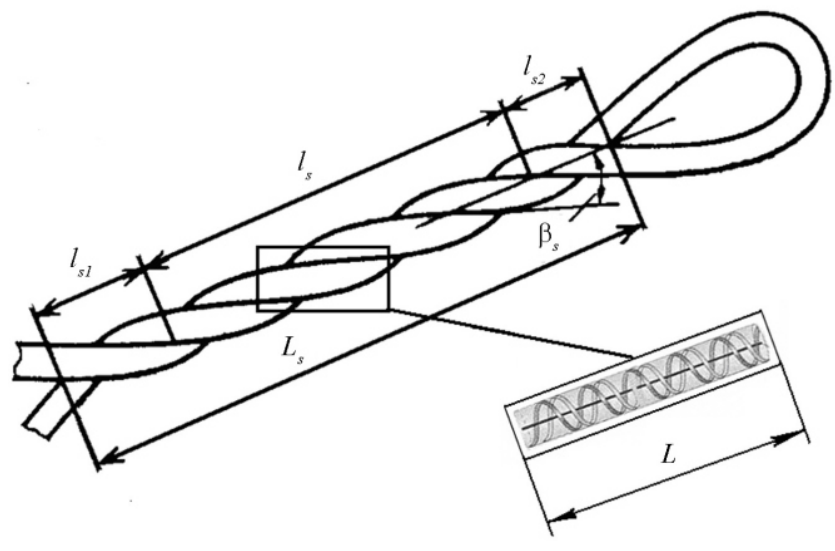

Fig.1 The scheme of supercoiled site of DNA (strand)
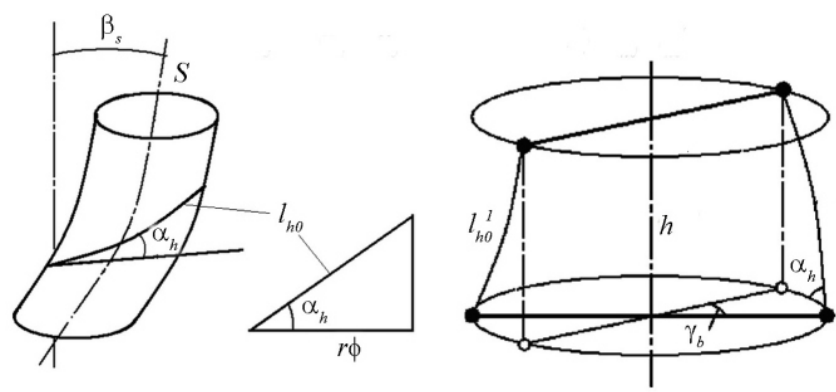

Fig. 2 The relation between geometrical parameters of DNA molecule

molecule it was chosen DNA model as an elastic rod with inner helical structure. The proposed structure stipulates anisotropy of the topological properties of supercoiled DNA molecules although the elastic properties of the model are isotropic. According to the previous data $[16,17]$, own twisting of double helix $\tau_{\mathrm{h}}$, which is rotation angle of cross-section of the molecule for the unit of its outline length, can be expressed through the strand angle $\beta_{\mathrm{s}}$ :

$$
\tau_{h}=\Omega_{0}+\frac{a_{g} \operatorname{tg}^{3} \beta_{s}-\operatorname{tg} \beta_{s}}{r\left(1-\operatorname{tg}^{4} \beta_{s}\right)},
$$

where $\Omega_{0}=2 \pi / \mathrm{H}_{0}$ is the twisting at the unstrained state $\left(\mathrm{H}_{0}\right.$-helix pitch of relaxed DNA), $\mathrm{g}_{\mathrm{b}}=2.7 \cdot 10^{-28}$ $\mathrm{Nm}^{2}, \mathrm{~g}_{\mathrm{t}}=2.1 \cdot 10^{-28} \mathrm{Nm}^{2}$ - the bending stiffness and torsional stiffness of DNA correspondently $[18,19]$, $\mathrm{a}_{\mathrm{g}}=1+2 \mathrm{~g}_{\mathrm{b}} / \mathrm{g}_{\mathrm{t}}=3.57$; all parameters of double helix are marked here with " $h$ ". It is important to notice, that formula (3) was obtained subject to self contact of the molecule branches, which are at the strand state. It appears from the formula, that under relaxed state, when $\beta_{\mathrm{s}}=0$, we got $\tau_{\mathrm{h}}=\Omega_{0}$. The change of the strand angle leads to the change of $\tau_{\mathrm{h}}$ and, therefore can induce superhelix. Then the conditions of positive and negative superhelix can be simplified: if $\tau_{\mathrm{h}}>\Omega_{0}$, superhelix is positive, if $\tau_{\mathrm{h}}<\Omega_{0}$, superhelix is negative.

Theoretical ground of the transition right-handed left-handed helix in plectonomical strand of DNA molecule. As it was shown in previous works [11-13], singular DNA molecule is subjected to different force factors. So, it is possible to model the situation, when under influence of outer force factors the strand is formed in wide ranges of the angles . $\beta_{\mathrm{s}}$ The relationship between geometrical parameters of DNA can be established according to schemes given in Fig. 2: on the left side there is one of two strand branches, in the centre you can see the sweep of sugar phosphate backbone, on the right side there is a structural component of DNA molecule containing two base pairs.

We can express $\tau_{\mathrm{h}}$ through the angle of ascent of sugar phosphate backbone $\alpha_{\mathrm{h}}$ (Fig.2):

$$
\tau_{h}=\frac{d \varphi}{d l_{h 0}} \frac{d l_{h 0}}{d s}=\frac{\cos \alpha_{h}}{r} \frac{1}{\sin \alpha_{h}}=\frac{1}{r \operatorname{tg} \alpha_{h}},
$$

where $1_{h 0}$ is the length of sugar phosphate backbone; $\mathrm{s}$ is an angular position changing along the double helix axe; $\varphi$ - is an angle, which determines sugar phosphate backbone position with the change of $\mathrm{s}$ (along the length $\Delta \mathrm{s}=\mathrm{h}$ we have $\Delta \varphi=\gamma_{\mathrm{b}}$, see Fig. 2). To define the task solution we picked out the DNA fragment from the regular site of the strand (Fig 1). The length of the $\mathrm{L}$ fragment under relaxed state corresponds 10 full turns of DNA double helix, i.e. $\mathrm{L}=\mathrm{L}_{0}=10 \mathrm{H}_{0}=34 \mathrm{~nm}$. The length of the $\mathrm{L}$ fragment was arbitrary chosen. It has to be in the limits of the regular site of the strand, $1_{s}$ (Fig. 1). The linking number $\mathrm{Lk}_{0}$ for this DNA fragment under relaxed or circular state is equal to the number of full turns, which makes one chain of DNA sugar phosphate backbone around the axe of the double helix : $\mathrm{Lk}_{0}=\mathrm{Tw}_{0}=10$. This state we can consider as initial one, when we will observe the change of both: geometry and topology of the chosen fragment during molecule supercoiling.

The length of sugar phosphate backbone, corresponding to 10 full turns of the double helix of the 


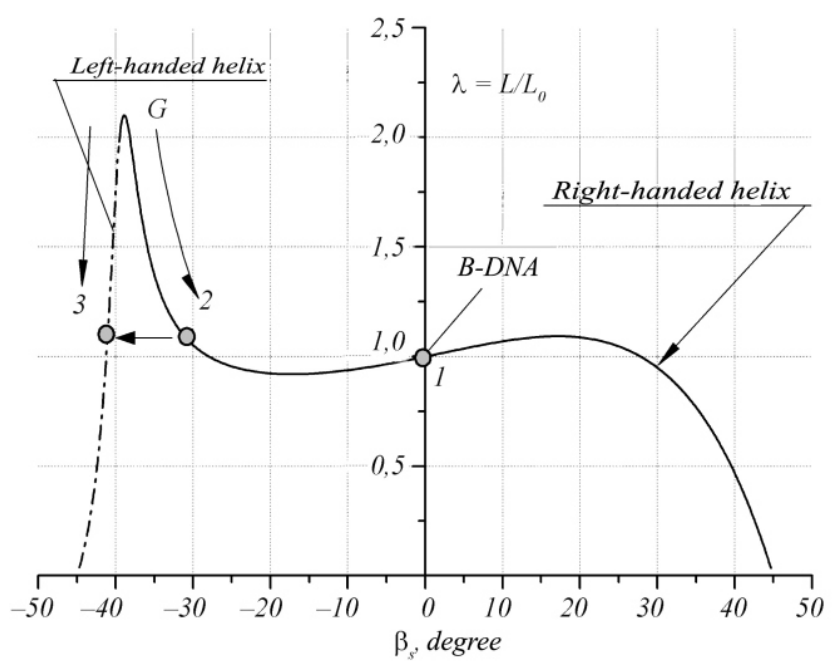

Fig. 3 Dependence of supercoiled DNA magnification on the strand angle.

relaxed DNA (Fig. 2, the central part) can be defined as following:

$$
l_{h 0}=10 \sqrt{(2 \pi r)^{2}+H_{0}^{2}}=10 n_{b} l_{h 0}^{1}=71,5 \mathrm{~nm},
$$

where $n_{b}$ is the number of base pairs for one full turn of the double helix; $1_{\text {ho }}^{1}$ is the distance along sugar phosphate backbone between two neighboring bases (Fig. 2, on the right).

We can make some suggestion: 1) the backbone is inextensible, its length, $1_{\mathrm{h} 0}=71.5 \mathrm{~nm}$ will be constant (so we provide topological limit); 2) base pairs are rigid, so the molecule radius could not be changed during supercoiling. ( $\mathrm{r}=$ const). We made the first suggestion taking into consideration the fact, that deformation of the backbone extension is negligible as compared with its twist and bend deformation. When there is a change of own twisting $\tau_{h}$ conditioned by the formation of the strand with different $\beta_{s}$, the current contour length, $L$ of the chosen fragment is also changed. It becomes either more than $\mathrm{L}_{0}$ in case of negative superhelix (the molecule is untwisted) or less than $\mathrm{L}_{0}$ in case of positive superhelix (the molecule is twisted). We can explain this statement in detail. Taking into account expression (4) and Fig.2, we can calculate the current length of the chosen DNA fragment in the following way:

$$
L=l_{h 0} \sin \alpha_{h}=\frac{1}{\sqrt{1+r^{2} \tau_{h}^{2}}} .
$$

Substituting in (6) the value of $\tau_{\mathrm{h}}$ from (3), we can find $\lambda$, magnification of the molecule: $\lambda=\mathrm{L} / \mathrm{L}_{0}$ (ratio of the current length $L$ to the length of the same fragment under relaxed state $\mathrm{L}_{0}$ ). This magnification can be expressed as a function of the strand angle $\beta_{\mathrm{s}}$. This relationship is presented at Fig. 3. Under the influence of external factors the strand can be left-handed (angle $\beta_{\mathrm{s}}$ has negative values) or right-handed ( $\beta_{\mathrm{s}}$ has positive values). We can consider DNA superhelix as the positive one when $\beta_{\mathrm{s}}>0$ and the negative one when $\beta_{\mathrm{s}}<0$. This interpretation can be explained by the fact, that $\beta_{\mathrm{s}}$ change induces the change of own twisting $\tau_{\mathrm{h}}$, i.e. it induces superhelix. Positive superhelix is observed when nitrogen bases turn in the plane, which is perpendicular to the double helix axe in the line of helix run (see Fig.2, on the right the upper base turns clockwise relatively the bottom base). That is why the upper base step-by-step approaches towards the bottom one (because of the presence of sugar phosphate backbone) and in an ideal case, if stacking interaction between bases is not taken into account, the distance between them is theoretically equal zero, however, in effect it is not possible thanks steric limit. In this case the angle of ascent of helical line $\alpha_{h}$ verges towards 0 . That is an evidence of full twisting of DNA molecule, when double helix is interlocked. At the negative superhelix the bases move away from each other, the length of the molecule increases and, as it was shown at Fig.3, when $\beta_{\mathrm{s}}=-39^{\circ}$ it achieves its limiting value, i.e. it is completely untwisted (the angle of ascent of helical line $\alpha_{h}$ verges $\pi / 2$ ). According to (6) this length is equal $\mathrm{L}=\mathrm{l}_{\mathrm{h} 0}=71.5 \mathrm{~nm}$ and $\lambda=\mathrm{L} / \mathrm{L}_{0}=2.1$.

In both cases (positive and negative superhelix) until $\beta_{\mathrm{s}}=-39^{\circ}$ the DNA molecule is a right-handed helix (solid line at Fig.3). When the strand angle has value more than $-39^{\circ}$, the length of the molecule is sharply decreased. To our mind in this case the new left-handed DNA is formed (dash-and-dot line at Fig.3). It is possible, that transition from the right-handed helix to left-handed one is not accompanied with the full untwisting of the double helix (see curve 2G3, Fig. 3), but has stick-slip crossing character, from point 2 to the point 3.

To prove the left-handed helix formation in our model, we calculated the main geometrical parameters of the molecule, which is at the state described by the 
point 3 (see Fig.3). We established, that the angle between neighbor base pairs is equal $\gamma_{b}=-31.7^{\circ}$, the distance between them is $\mathrm{h}=0.453 \mathrm{~nm}$, the number of the nitrogen base pairs for one pitch of helix $n_{b}=11.36$. The obtained parameters are close to Z-form geometrical parameters [20], however, according to our model, it is not correct to speculate about Z-form. This result proved the fact, that not only plectonomical strand could be left-handed or right-handed, but also DNA itself could form left-handed or right-handed helix in this strand.

\section{The calculation of DNA topological} characteristics under supercoiled state. We can investigate the changes of linking characteristics Lk, $\mathrm{Wr}$ and Tw subject to the strand angle $\beta_{\mathrm{s}}$. As it was shown here, the linking number $\mathrm{Lk}_{0}$ for the chosen DNA fragment staying at linear (or circular) relaxed state is equal to the number of full turns, which one chain of sugar phosphate backbone makes around the helix axe, i.e. $\mathrm{Lk}=\mathrm{Tw}=10$. We have to notice, that we consider the site of plectonomical strand for the length $1_{s}$ (Fig. 1). In this range the strand is regular, i.e. the angle $\beta_{\mathrm{s}}$ is the same along the whole length $1_{\mathrm{s}}$.

At the site ls the characteristic of axial line form Wr depends on the turn number of the axial line Ns, the molecule around strand axe and on the value of strand angle $\beta_{\mathrm{s}}$. Using [15], we can get the following equation

$$
W r=N_{s}\left(1-\left|\cos \beta_{s}\right|\right) .
$$

The expression for the turn number of the axial line of the chosen site of the molecule around strand axe is determined by the sweep of this axe:

$$
N_{s}=\frac{L \sin \beta_{s}}{2 \pi r} .
$$

Taking into consideration (8), we can express Wr in the following way:

$$
W r=\frac{L \sin \beta_{s}}{2 \pi r}\left(1-\left|\cos \beta_{s}\right|\right) .
$$

(6)

In this case the length $\mathrm{L}$ in (9) is calculated using

The twist characteristic Tw we can obtain from its definition:

$$
T w=\frac{1}{2 \pi} \int_{0}^{L} \Omega d s .
$$

Twist deformation $\Omega$ is determined, according to [16], in the following way

$$
\Omega=\frac{\sin \beta_{s} \cos \beta_{s}}{r}+\tau_{h},
$$

So

$$
T w=\frac{\Omega L}{2 \pi}=\frac{L}{2 \pi}\left(\frac{\sin \beta_{s} \cos \beta_{s}}{r}+\tau_{h}\right),
$$

where $\tau_{\mathrm{h}}$ is calculated according to (3). Taking into consideration the equations (9) and (6) we presented the dependence of parameters $\mathrm{Wr}$ and Tw on the strand angle at Fig.4.

When $\beta_{\mathrm{s}}=0$ the considered site is relaxed, $\mathrm{Wr}=0$, $\mathrm{Tw}=10$ (Fig.4, point 1), so, according to (2) $\mathrm{Lk}=\mathrm{Tw}=\mathrm{Lk}_{0}=10$. If $\beta_{\mathrm{s}}>0$, the double helix axe is deformed and it is accompanied with $\mathrm{Wr}$ increase. The sharp decrease $\mathrm{Wr}$ at $\beta_{\mathrm{s}}>35^{\circ}$ is related with the fact, that length of DNA site, according to Fig. 3, tents to zero (however this is theoretical result and, probably, strand with the angle $\beta_{\mathrm{s}}>35^{\circ}$ is not realized). The point $G$ corresponds to the full DNA untwisting and it is the transition point from right-handed helix (1G) to left-handed helix (G3). The twist Tw at the point $\mathrm{G}$ reverses sign and the left-handed helix is formed at the site $\mathrm{G} 3$ (see Fig.4). At the point $\mathrm{G} \mathrm{Tw}=0$, so the linking number $\mathrm{Lk}=\mathrm{Wr}=-1.5$ and all superhelix is formed as a result of the double helix bend, i.e. as a result of supercoiling. To compare theoretical data with experimental ones [13] we can plot superhelix density $\sigma=\left(\mathrm{Lk}_{\mathrm{L}} \mathrm{Lk}_{0}\right) / \mathrm{Lk}_{0}$ as a function of magnification $\lambda=\mathrm{L} / \mathrm{L}_{0}$ (see Fig.5). As it is seen, the point 1 corresponds to zero superhelix density. When superhelix is positive the molecule is twisting and, as it was shown at Fig.5, the magnification $\lambda$ tents to zero. It is notable that the same value of $\sigma$ can correspond to two different states with the certain $\lambda$ values.

Positive and negative superhelix are not symmetric. As it is seen at Fig.5, the maximal number of the positive supercoils is considerably less $(\sigma=+0.26)$, than the number of the negative ones $(\sigma=-2.3)$. It proves the fact, that negative superhelix can be realized in the wider range, than the positive one. Behavior of 


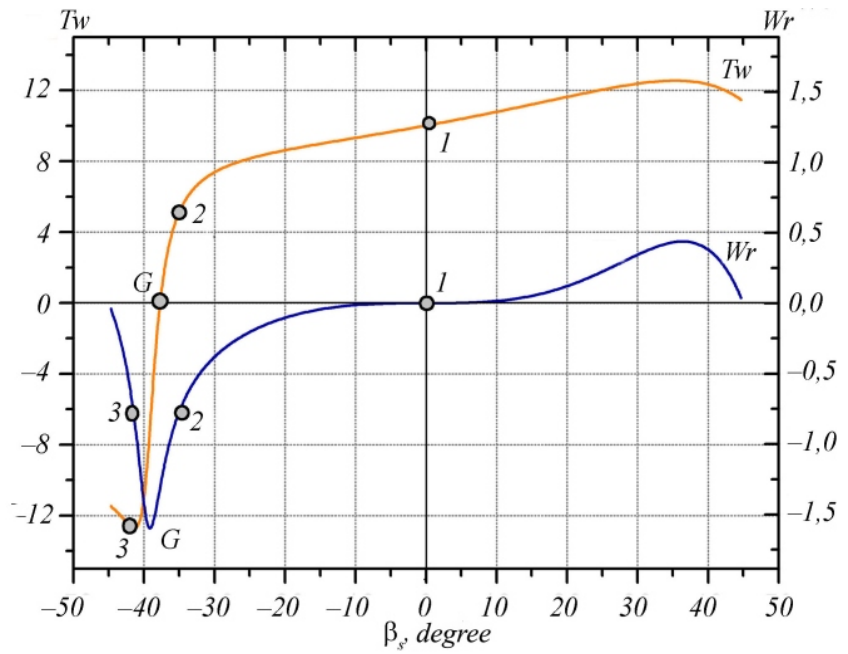

Fig.4. Dependence of writhing number $W r$ and twisting $T w$ on the strand angle $\beta_{s}$.

function $\lambda=\lambda(\sigma)$ (see Fig.5) is in accordance with experimental data described in [13]. According to this work, at the positive superhelix when $\sigma$ is in the range from +0.025 to +0.1 , Poling-like DNA structure is observed. This structure is characterized by the strong approaching of the base pairs when some of them can partially go out. Our calculation showed, that positive superhelix is accompanied with the approaching of the base pairs at $\sigma \geq 0.2$, in the extreme case it leads to theoretical interlocking of DNA helix. According to experimental data obtained in [13], at negative superhelix when $\sigma$ is in the range from -0.01 to -0.1 the breaks in hydrogen bonds between base pairs are fixed. Observed in this work partial DNA denaturation can be induced by the character of force loading of the molecule and can be also related with experimental specificity. According to our theoretical and previous experimental data [13], when $\sigma$ is in the range from -0.01 to +0.025 , the molecule is in the form similar to B-DNA. Considering the molecule behavior at $\sigma<0.1$, we can notice, that the description of this region is theoretical prediction and can support the idea about possible formation of left-handed DNA helix in plectonomical strand.

The estimation of inner force factors in the branches of DNA strand. Experimental determination of inner force factors in the plectonomical DNA strand is rather difficult, that is why their estimation based on

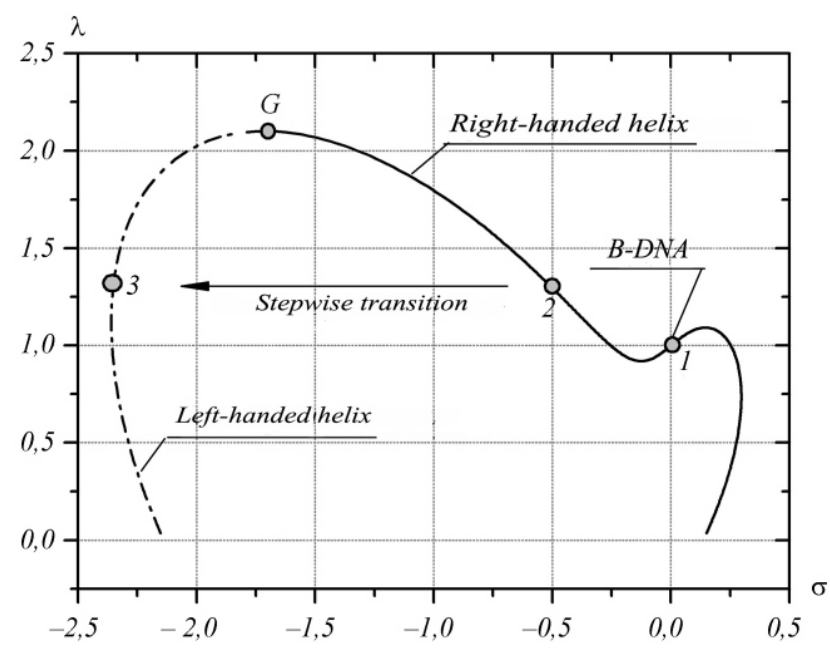

Fig.5. Dependence of superhelix density $\sigma$ on the magnification $\lambda$.

the developed theoretical model is a very important task. The DNA model proposed in this paper takes into account self-contact of the branches in the plectonomical strand, so it is possible to estimate the change of contact interactions as a function of strand angle. The bending moment $\mathrm{Mb}$ and twisting moment Mt are related with strand angle in the following way $[16,17]$ :

$$
M_{b}=g_{b} \frac{\sin \beta_{s}}{r} \text { и } M_{t}=g_{t}\left(\Omega-\Omega_{0}\right) .
$$

If we put the value of $\Omega$ from (10) expressed as a function of strand angle in the relation obtained for twisting moment we can get the following:

$$
M_{t}=\frac{g_{t}}{r} \frac{\left(a_{g}-1\right) \operatorname{tg}^{3} \beta_{s}}{1-\operatorname{tg}^{4} \beta_{s}}=\frac{2 g_{b}}{r} \frac{\operatorname{tg}^{3} \beta_{s}}{1-\operatorname{tg}^{4} \beta_{s}} .
$$

It is interesting, that there is no torsional stiffness gt in the final expression (13) and twisting moment is determined by bending stiffness gb.

As it follows from (13), the value of twisting moment is an antisymmetric function of the strand angle. It proves the idea, that direction of the outer twisting moment applied, for example, to the ends of the molecule (see Fig.2) is able to lead to the formation of right-handed or left-handed strand. The expressions (12) and (13) give us the possibility to calculate bending and twisting moments and, therefore, other 

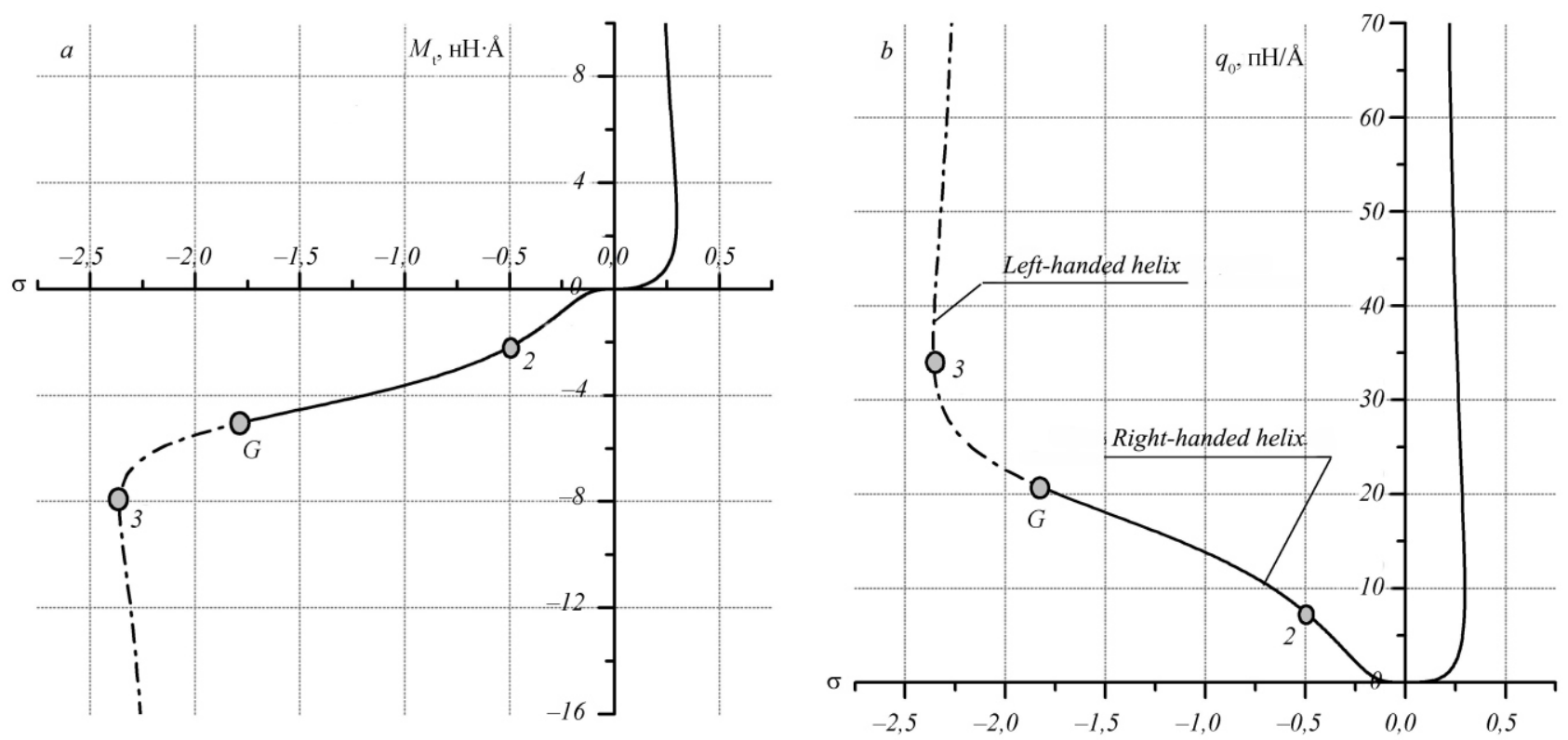

Fig.6. The dependence of inner twisting moment $(a)$ and contact load between strand branches $(b)$ on the superhelix density.

force factors of supercoiled DNA molecule at any strand angle. So, it is possible to calculate the contact load with intensity $\mathrm{q}_{0}$, which appears between the branches of plectonomical DNA strand. Using the expressions for bending or twisting moment and taking into account of the results obtained in [17], we can get the following:

$$
\begin{aligned}
q_{0} & =\frac{M_{t} \operatorname{tg} \beta_{s}}{2 r^{2}}=\frac{g_{t}}{r^{3}} \frac{\left(a_{g}-1\right)}{2} \frac{\operatorname{tg}^{4} \beta_{s}}{1-\operatorname{tg}^{4} \beta_{s}}= \\
& =\frac{g_{b}}{r^{3}} \frac{\operatorname{tg}^{4} \beta_{s}}{1-\operatorname{tg}^{4} \beta_{s}}, \\
q_{0} & =\frac{M_{b} \operatorname{tg}^{2} \beta_{s}}{r^{2}\left(1-\operatorname{tg}^{2} \beta_{s}\right)}=\frac{g_{b}}{r^{3}} \frac{\operatorname{tg}^{4} \beta_{s}}{1-\operatorname{tg}^{4} \beta_{s}} .
\end{aligned}
$$

It is notable, that contact load in (14), besides the strand angle, depends on bending stiffness gb and does not depend on torsional stiffness gt. It is also possible to define lateral $(\mathrm{Q})$ and longitudinal $(\mathrm{N})$ forces appearing in the strand [17]:

$$
Q=q_{0} \frac{r}{\operatorname{tg} \beta_{s}}=\frac{g_{b}}{r^{2}} \frac{\operatorname{tg}^{3} \beta_{s}}{1-\operatorname{tg}^{4} \beta_{s}},
$$

and

$$
N=q_{0} r=\frac{g_{b}}{r^{2}} \frac{\operatorname{tg}^{4} \beta_{s}}{1-\operatorname{tg}^{4} \beta_{s}} .
$$

As it is seen from (13)-(15), all force factors can be expressed only as functions of bending stiffness $\mathrm{gb}$ and strand angle $\beta_{\mathrm{s}}$.

The superhelix density sis an experimentally determined value. To determine the precise value of strand angle $\beta_{\mathrm{s}}$ is more complicated task especially as because the transition from right-handed helix to left-handed one takes place in the narrow range of $\beta_{\mathrm{s}}$ values (see Fig.3). So the dependence of force factors on the superhelix density $\sigma$ is more valuable, than their dependence on the strand angle $\beta_{\mathrm{s}}$. The most interesting results we presented at Fig.6 where we showed dependence of inner twisting moment $\mathrm{Mt}$ (if we divide it into polar moment of the resistance we can get torsional stress in the molecule) and intensity of contact load between strand branches $\mathrm{q}_{0}$ on superhelix density $\sigma$. As we can see at Fig.6, the formation of left-handed helix (site G3) is not accompanied with stepwise changes of inner force factors unlike magnification (Fig.3, site 2G3), particularly, inner twisting moment during formation of left-handed DNA helix in plectonomical strand gradually increases. The point 3 at the diagrams corresponds to maximum possible negative superhelix density $\sigma=-2.3$. At the positive superhelix, which takes place in the considerably less range, the maximal degree of positive supercoils is $\sigma=0.26$. The following increase of twisting moment 
has no influence on the increase of positive supercoils, but it is accompanied with energy accumulation. When the energy achieves its critical value, it is possible the slip of the bases out of the molecule with the formation of Poling-like DNA. Using the presented dependence and knowing experimental value of superhelix density, we can estimate inner force factors in plectonomical DNA strand. It is not possible to do by experimental way at the moment. As we can see at Fig.6, the region of left-handed helix existence (dash-and-dot line) at the site G3 corresponds to the region of "stress", which can be formed in DNA molecule. So, from the force point of view, the formation of left-handed helix is also well founded.

Conclusions. On the base of DNA model realized as an elastic rod with the inner helical structure, where self-contact of the branches was taken into account, we have deduced formula for topologic DNA characteristics depending on strand angle. We think that it is an important result, which can be used in practice. It was founded the transition from right-handed helix to left-handed one, which is theoretically possible in plectonomical strand of the molecule at the certain value of the angle $\beta_{\mathrm{s}}$. The dependence for calculation of inner force factors was obtained. We have also done a very important theoretical definition for the ranges of superhelix process $(-2.3 \leq \sigma \leq 0.26)$.

So, the presented here results of theoretical investigations broaden the conception, concerning elastic properties of DNA molecule in supercoiled state, and let us predict and interpret the experimental data.

The work was done at the Department of theoretical mechanics, Belorussian state technological university by support Belarusian Republican Foundation for Fundamental Research, grant N F07M-024.

\section{А. В. Ширко, А. Н. Камлюк}

Топологические и силовые характеристики ДНК, находящейся в сверхскрученном состоянии

Резюме

На основе методов теории упругости проведено моделирование топологических свойств сверхскрученных ДНК. Установлен механизм реализации топологических ограничений для сверхскрученных ДНК. Теоретически обоснована возмож- ность перехода от правосторонней к левосторонней ДНК в свивке молекуль. Исследовано влияние угла свивки на топологические характеристики молекулы. Определены параметры силового контактного взаимодействия в ветвях свивки.

Ключевые слова: топология, угол свивки, переход «правая спираль-левая спираль», силовые характеристики.

\section{А. В. Ширко, А. М. Камлюк}

Топологічні та силові характеристики ДНК, яка перебуває у надскрученому стані

Резюме

Методами теорії пружності змодельовано топологічні властивості надскрученої ДНК. Встановлено механізм реалізаціі топологічних обмежень. Теоретично обтрунтовано можливість переходу від правосторонньої до лівосторонньої ДНК у звиві молекули. Досліджено вплив кута звиву на топологічні характеристики макромолекули. Визначено параметри силової контактної взаємодії у гілках звиву.

Ключові слова: топологія, кут звиву, перехід від правосторонньої до лівосторонньої спіралі, силові характеристики.

\section{REFERENCES}

1. Shirko A. V., Kamluk A. N., Nemtsov V. B. Research of the configuration of the DNA macromolecule ring by the methods of the elasticity theory // Reports of National Academy of Sciences of Belarus.-2007.-51, N 1.-P. 34-39.

2. Shirko A. V. Statistiko-mechanicheskoe opisanie nelineynoy uprugosti molekuly DNK: Avtoref. dis. ... kand. fiz.-mat. nauk / In-t fiziki im. B. I. Stepanova NAN Belarusi.-Minsk, 2008. $-22 \mathrm{~s}$

3. Furrer P. B., Manning R. S., Maddocks J. H. DNA rings with multiple energy minima // Biophys. J.-2000.-79, N 1.P. 116-136.

4. Boles T., White J., Cozzarelli N. Structure of plectonomically supercoiled DNA // J. Mol. Biol.-1990.-213, N 4.-P. 931951.

5. Adrian M., ten Heggeler-Bordier B., Wahli W., Stasiak A. Z., Stasiak A., Dubochet J. Direct visualization of supercoiled DNA molecules in solution // EMBO J.-1990.-9, N 13.P. 4551-4554.

6. Limanskaya L. A., Limanskii A. P. S-DNA is oversupercoiled DNA with 1.94-2.19 Ärise per base pair // Molecular. Biol. (Russia).-2006.-40, N 1.-P. 122-136.

7. Bednar J. The twist, writhe and overall shape of supercoiled DNA change during counterion-induced transition from a loosely to a tightly interwound superhelix // J. Mol. Biol.1994.-235, N 3.-P. 825-847.

8. Yang Y., Tobias I., Olson W. K. Finite element analysis of DNA supercoiling // J. Chem. Phys.-1993.-98, N 2.P. 1673-1686.

9. Tobias I., Swigon D., Coleman B. D. Elastic stability of DNA configurations. I. General theory // Phys. Rev. E.-2000.- 61, N 1.-P. 747-758.

10. Coleman B. D., Swigon D., Tobias I. Elastic stability of DNA configurations. II. Supercoiled plasmids with self-contact // Phys. Rev. E.-2000.-61, N 1.-P. 759-770. 
11. Allemand J. F., Bensimon D., Lavery R., Croquette V. Stretched and overwound DNA forms a Pauling-like structure with exposed bases // Proc. Nat. Acad. Sci. USA.-1998.-95, N 24.-P. 14152-14157.

12. Strick T. R., Croquette V., Bensimon D. Homologous pairing in stretched supercoiled DNA // Proc. Nat. Acad. Sci. USA.1998.-95, N 18.-P. 10579-10583.

13. Lionnet T., Joubaud S., Lavery R., Bensimon D., Croquette V. Wringing out DNA // Phys. Rev. Lett.-2006.-96, N 17.P. 178102-1-4.

14. Leger J. F., Romano G., Sarkar A. Structural transitions of a twisted and stretched DNA molecule // Phys. Rev. Lett.1999.-83, N 5.-P. 1066-1069.

15. Frank-Kamenetckii M. D., Vologodskii A. V. Topological aspects of physics of polymers: the theory and its biophysical appendices // Physics Uspekhi.-1981.-134, N 8.-P. 641673.
16. Kamlyuk A. N., Shirko A. V., Nemtsov V. B. Geometric features of the DNA double helix in the supercoiled state // Biophysics (Russia).-2007.-52, N 1.-P. 19-23.

17. Nemtsov V. B., Kamluk A. N., Shirko A. V. Contact interactions of branches of superspiral DNA molecules // Trudy BSTU. Series VI. Physico-mathematical sciences and informatics.-2004.-Issue XII.-P. 62-66.

18. Moroz J. D. Nelson P. Entropic elasticity model of twist-storing polymers // Macromolecules.-1998-31, N 18.-P. 63336347.

19. Bouchiat C., Mezard M. Elasticity model of a supercoiled DNA molecule // Phys. Rev. Lett.-1998.-80, N 7.-P. 15561559.

20. Saenger $W$. Principles of nucleic acids structure.-New York etc.: Springer, 1984.-556 p.
UDC 536.758

Received 16.04.08 